\title{
University-Industry Relations and Technological Convergence
}

\author{
Fernando Romero \\ University of Minho, Department of Production and Systems, Guimaraes, Portugal
}

\begin{abstract}
University-industry relationships and the associated diversity of multi-institutional networks of researchers are phenomena that have important implications in terms of the management of technological integration. The nature of these peculiar relationships has inherent knowledge generation characteristics that may be particularly suitable to the task of integrating different approaches and different technologies in novel ways. This paper attempts to systematize and synthesize recent literature on the subject. It focuses on the relationships between forms or modes of academia and industry cooperative channels and their implications on knowledge production and exploitation. It explores their contribution in terms of its potential as a tool that can be used in the management of technological convergence. It presents relevant or illustrative examples, describing the main empirical findings and their important contributions, and it proposes a model that conceptualises the problem.
\end{abstract}

\section{INTRODUCTION}

This paper explores the phenomena of universityindustry relations (UIR) and its relationship to the management of technological convergence. The first three sections draw on theoretical concepts from different areas to contextualise the phenomena. The two following sections describe several relational processes concerning interactions between researchers in the university and in the firm. The remaining sections, building on the previous ones, explore the notion of technological convergence in the context of university-industry relations.

\section{TRENDS IN UNIVERSITY-INDUSTRY RELATIONS}

Relations between university and industry are not new and they have changed with the evolution of the university itself, the evolution of industry and the policy initiatives and objectives surrounding the university institution. The origins of the modern research university, as we know it today, can be traced back to the second half of the nineteenth century, whereby the main values that described the institution were:1) the production of knowledge for its own sake; 2) the preparation for professional careers; 3 ) a structure based on well -defined disciplines and 4) an articulate organisation and a legal status [17]. The university was already seen as a National institution and its mission was related to the development of the nation-state. Explicit orientation to the needs of the local or regional economy was stronger in the United States universities than in the European ones, where research "for its own sake" was the predominant approach. During the $20^{\text {th }}$ century, institutional diversification and expansion gave birth to a set of "higher education" institutions that had diverse approach as it concerned relations with industry or local economic needs and/or emphasis on "pure" research. After the $2^{\text {nd }} \mathrm{WW}$, the role of science and technology in terms of its direct applicability to economic development was firmly established among the western nations, although a linear perspective of the innovation process persisted. Governments diverted huge resources to research and development (not only to universities but also to other public agents) in the belief that such an investment, through a "pipeline" mechanism, would be transfigured into new processes and products and ultimately in increased wealth. More recently, several factors have transformed the way the university approaches its relations with industry. The perception that the innovation process is not a linear one and that the activities of basic research and development have and need innumerable connections, the increasing complexity of science and technology and the associated uncertainty and risks in the development of new products and processes, and the proliferation of public and private actors that are engaged in research and development activities, has put new demands and pressures on the university system.

Increasing connections between academia and industry are visible in several indicators. Statistics on the percentage of total expenditure on R\&D performed by the Higher Education sector that is financed by the Business sector [36], including the EU15 countries plus Canada, Japan and USA, show a percentage of $2.2 \%$ in 1981 and a percentage of $5.5 \%$ in 2001 . There is a wide diversity between countries, and the percentages vary from $1 \%$ to $13 \%$. The USA is on the middle of the league. During the 1980 decade, there is a very rapid rate of increase (averaging 15\% per year) and during the 1990s and 2001, the rising trend persists but at a slower and declining rate (about $4.5 \%$ per year). The pattern of growth during the first period is probably related to the development of new science, whereas the pattern of growth during the last period is tentatively related to natural constrains or opportunities that limit the usefulness and growth of UIR.

According to several reports $[34,35]$ both the relative and the absolute number of publications co-authored by industry and university researchers are also increasing.

The number of scientific papers that is cited by patents is also increasing, showing the impact that academic research is having on industrial inventive activity. Technological innovation makes increasing use of academic research output but the intensity and the degree of connection seems subject to considerable variability across fields.

The number of firms that are created base on university research (spin-off firms) is also growing. 


\section{UNIVERSITY-INDUSTRY RELATIONS AND SOCIAL NETWORK THEORIES}

The advantages of having relationships with a wide variety of actors in diverse institutional settings have long attracted the attention of scholars [16]. There are a few sociological concepts that help explain the mechanisms of information diffusion and knowledge exchange within or across networks. Granovetter [19] proposes the concepts of strong and weak ties. A strong tie represents a person with whom there is a regular interaction, and a weak tie represents a person with whom there are sporadic or punctual contacts. The source of much of new information that a person receives comes from weak ties, while strong ties are important in terms of day to day social interaction and support. Weak ties are the source of new ideas or new perspectives at looking at old problems. Strong ties are relevant in the exchange of complex information and conducive to the exchange of detailed and thick information [1]. Applying these concepts to UIR, we can consider that researchers in academia are in a day-by-day basis in contact with their peers, their colleagues, with whom they share and construct complex information, but based on common beliefs and common approaches to solve problems (strong ties). The same can be said of researchers in an industrial setting. Complex and detailed information concerning that setting is shared between colleagues and co-workers, but is common that a unique problem solving paradigmatic approach prevails among the group. If a relationship is formed between a member of this group and a member of the academic group (weak tie), there is a high probability that new and fresh insights into old problems may occur, because of the different intellectual trajectories, constructs and perspectives that each individual brings with them. New possible knowledge combinations, otherwise difficult to obtain if the individuals were kept apart, can result from that interaction, and this applies to both sides of the relation.

Another conceptual perspective is the distinction between networks as bridges and networks as structural holes [8]. Elements of a network may connect differently and with different persons. If a person knows another person in a network but a third person only knows the second, there is a not yet realised potential of connection between this last person and the first one. This configuration was defined by Burt as a structural hole, meaning the connection potential between elements or groups of elements that are not connected. There are elements that are better positioned than other to bridge and broker these gaps in the structure of the network, either to their own advantage or based on mediation and arbitration [33].

This discussion highlights the advantages of universityindustry relations (UIR), in terms of the enhancement of the opportunities for new, complementary or convergent approaches to technological bottlenecks or opportunities faced by industry, and by opening new avenues of research and product development, both for members of academia and industry. Researchers in industry and researchers in academia have very different perspectives, experiences, and sensibilities and, in this sense, the two communities have inherent knowledge production advantages by creating communication channels and patterns of cooperation.

\section{UNIVERSITY-INDUSTRY RELATIONS AND ECONOMIC THEORIES OF INNOVATION}

The discussion concerning UIR is related to the quest for optimal allocation of resources for knowledge production between public (e.g. universities) and private institutions (e.g. firms). In terms of economic theory, the concern is to maximise the social returns of that investment distribution. The discussion is complicated by the fact that knowledge has a public good nature that affects the way private and public returns are appropriated. Public goods are characterised by non-rivalry and non-excludability, meaning that is difficult, or impossible, to assure exclusive access to them, as well as to have exclusive fruition of them. The nature of knowledge is conducive to a division of labour between basic research and applied research. Basic research, whose outcome is generally codified, and whose appropriability is low should be performed by public institutions. The applied or goal oriented research, which implies, in general, an emphasis on tacit (non-codifiable) knowledge, which is more easily appropriated by the producer of that knowledge, is performed by profit seeking institutions. Under this linear perspective, the motivation for private firms to enter into relationships with universities would be to get access to basic knowledge, since the incentive of firms to invest internally in basic research would be too low.

If a non linear perspective of the process of knowledge creation and exploitation is adopted, other economic motivations may surge for firms to enter into relations with university. There are explicit links and feedback loops between basic research and applied or goal oriented research [41]. As such, firms need, or are obliged by the very nature of the process of technological development, to engage in basic research activities in order to fully exploit technological opportunities. Firms have to build a minimum, or at least attain a threshold, of internal capacities in order to be able to absorb and integrate profitably in their own product or service portfolio knowledge generated externally [9].

Firms contribute to scientific advancement when generating innovative solutions to technical bottlenecks faced in their design or production phases [23], and through the development of new scientific instruments [44]. The division of labour between public and private entities and the reasons for firms and universities to interact are thus more complex than a simple linear perspective would lead us to believe.

This discussion between allocation of research activities between public and private entities is related to the issue of technological convergence in the sense that, in spite of the complexity and non-linearity of the technology integration process, there are preferred loci where new scientific ant 
technological avenues are initially carved out, setting the ground and permitting posterior convergence with existing or novel scientific and technological avenues, and embodying the potential for commercial or other applications.

\section{FROM COLLABORATION IN SCIENTIFIC NETWORKS TO UNIVERSITY-INDUSTRY RELATIONS}

Informal networks between individual researchers and between laboratories situated in different institutional settings or in different countries are as old as organized science and are inherent to the existence of "communities" of scientists and engineers belonging to the same discipline or working in the same or related field. Collaboration between scientists has been rising [28] and this trend may be related to changes in the organization of scientific work. There is a multiplication of team work after the mid twentieth century, related to public investment in large research projects. Team work has evolved to giant research projects, or "big science" as it is often called, of which the most common examples are related to high energy physics and aerospace research. Large projects in the field of molecular biology and biomedical research (e.g., the Genome project) have also introduced a truly networked and distributed form of organisation. Teamwork seems to represent a new paradigm in the organisation of scientific research, and marks a discontinuity with earlier research practices [5].

The trend in scientific collaboration is not divorced from the trends in university-industry cooperation. The practice of team-work has spread out to include participants that are external to the university. A bibliometric study, spanning a period of two centuries, on the collaboration between scientists [46], seems to indicate that collaboration (measured by co-authorship) increases in scientific fields that become, with time, more applied (to industrial applications). Collaboration intensity is not due to funding or specialization (which are commonly advanced causes) but by the application potential of theoretical science. That conclusion is in accordance with other empirical results, showing that the intensity of university-industry is sector specific, and is greater, for instance, in the biotechnology, ICT or aerospace fields $[12,32,43]$, sectors in which there has been a huge trend towards technological convergence or integration.

The growth and spread of knowledge-intensive firms has revived and accentuated the importance of UIR and the role of research and development within the network knowledge relationships [4, 27, 37, 39, 45, 47].

\section{MOTIVATIONS FOR UNIVERSITY-INDUSTRY COLLABORATION}

Asides from the theoretically-based sociological or economic arguments that contextualise university-industry interactions, there are a number of other commonly advanced causes to explain the rise in UIR. They include the increase in multidisciplinarity and complexity of scientific and technological knowledge and the prohibitive costs of some projects, which extend beyond the capacities or competencies of any given institution, laboratory or discipline. Advances in information and communication technologies are also referred as an important cause for the rise in collaborative activities. These reasons are directly related to the problem of technological convergence.

Bonaccorsi and Piccaluga [6] propose, from the point of view of the firm, a classification of the motivations for entering an university-industry relation, which is corroborated in many other studies [13, 14, 25, 42]:

1. Obtaining early access to scientific breakthroughs.

2. Increasing the predictive and applied power of science; includes modelling, training.

3. Delegating selected development activities; includes risk sharing, cost saving.

4. Lack of resources; e.g., getting access to laboratories and equipment.

From the point of view of the university, the motivations for establishing UIR are not so explored in the literature, but seem to fall in the following categories [2, 24]:

1. Knowledge motivations; to access or to interact with knowledge developed externally, in firms or other institutions, and to engage in oriented research.

2. Political motivations; policies have been set up to encourage scientific collaboration, motivated by the belief that collaboration maximizes public investment in research funding.

3. Financial motivation; the policies referred above have included a diminishing amount of government direct, structural funding of universities, as mechanisms to increase and encourage universities to self-finance through interactions with industry.

A comment is due in the first point, because the widespread notion in the literature is still that UIR are unidirectional relations, where industry is seeking knowledge from university, and not bidirectional, as it seems to be more the case [26]. That would explain why UIR are less intense in regions where industry is less developed [42], and why size of firm seems to be an important determinant of universityindustry interaction [15]. Large firms have generally built a stock of knowledge that is unique in many ways. Complementary between different research orientations seems to drive the exchange of knowledge in the common interests of both parts. This perspective is in line with sociological explanations.

\section{PERSPECTIVES ON UNIVERSITY-INDUSTRY RELATIONS AND TECHNOLOGICAL CONVERGENCE}

The sections above outlined the possible conceptual connections and set the ground for exploring the impact of university -industry relations on the management of technological convergence. Technological convergence is 
defined here as the confluence and merging of several hitherto disconnected strands of knowledge, originating products based on new combinations of elements or based on new scientific or engineering principles. Drucker [11] argues that "the computer,..., required no fewer than six separate strands of knowledge: binary arithmetic, Charles Babbage's conception of a calculating machine ..., the punch card..., the audion tube..., symbolic logic..., and the concepts of programming and feedback..." (p.71) Biotechnology requires the inputs from molecular biology, cell biology, genetics, bioinformatics, protein and combinatorial chemistry, and many others [38]. The reasons for the increase in UIR include motivations directly related to the need for managing and integrating disparate technological contributions and advancements in several and disconnected fields of research. Technological uncertainties and complementarities surrounding the integration process call for the participation of university actors that are capable of responding adequately in technical terms. The increase in inter-firm alliances is also a response to a technological environment that has become increasingly dynamic and complex. Hagedoorn [20] shows that interfirm research alliances have increased sharply since the mid-late 1970s, and that the main sectors involved in those alliances are high tech sectors (ICT, biotechnology, aerospace). Research partnerships are seen as mechanisms enabling firms to learn and enter new technological areas [21] and to deal more effectively with technological and market uncertainty. University industry relations are also connected to the dynamic necessity of firms to access new knowledge and to have access to insights on new or future advancements of science. Responses to a large survey on R\&D performing firms in the USA [10] “...suggest that the contribution of public research to industrial R\&D is principally via research findings, and this contribution is far greater than that of prototypes [built cooperatively]..." (p.8). The authors also found that the preferred channels for the information flow between academia and industry were related to those of "open science", namely publications, public meetings and conferences.

Public research organisations are an inescapable actor when the problem is related to convergence and technological integration. Historical accounts on the evolution of specific technologies all point to the crucial importance of public research organisations with respect to this integrative capacity.

In its account of the genesis of several scientific instruments, Rosenberg [40] shows the integrative function that university research has had with respect to the creation and diffusion of this particular segment of scientific research, and the broad impacts it had by virtue of its diffusion to disciplines, fields of application or activity different from their original ones. The example of the computer, which Rosenberg calls the "scientific instrument par excellence" (p.252) shows the convergence not only of diverse technology but also of diverse institutional contributions. In its remarkable account of the history of industrial automation Noble [31] describes in detail the multiple and disparate institutional and individual contributions to the integration and diffusion of science and technology. The case of instrumentation is elucidative in many respects, and in particular as it respects convergence and integration of technology, due to the widespread diffusion of instrumentation from one field of science to another, or from basic to applied problems or its diffusion into many areas of industrial application. Rosenberg [40] argues that "much of the equipment, perhaps most, that one sees in an up-to-date electronics manufacturing plants had its origin in the university research laboratory. In this sense, scientific instruments are now effectively indistinguishable from industrial capital goods." (p.256)

Shinn [44] stresses this argument even further and considers the radical nature of scientific instrumentation. He uses the term "research-technology" to denote a category of artefacts and a research community and methodology that has very specific characteristic. Acknowledging the post-modern situation of excessive cognitive and organizational fragmentation, he identifies the modes by which communication and knowledge transits between occupationally different groups. The "transverse" properties of the "research-technologies" identified by Shinn reside in the modus operandi of the "research-technologists", who "operate in an interstitial arena-acting in spaces that occur between established organizations" (p.754). Working in between organisational boundaries provides the researchers in this community freedom from pressures of vested interests and a very effective way of interaction with groups from disparate institutional affiliations and professional practices. Both Rosenberg and Shinn concur in the idea that convergence and integration of technologies in a radically new way and in ways that have widespread impacts in several fields of activities depend on organizational settings that necessary include close and intimate relationships with public research organisations.

Sectoral studies of innovative performance reinforce Shinn's argument that variety of communicating actors is a fundamental aspect of technological integration. Gittelman [18] compares the evolution of the commercial biotechnology industrial sector in France and in the USA, and concludes that the superior innovative performance of the USA biotechnology sector resides in the diversification of actors, and the openness of the communication, that compose the innovation networks behind the commercial sector. OwenSmith [37] arrived at similar conclusions in an earlier comparative study of the same biotechnology sectors in the USA and in Europe. The biotechnology sector is important concerning technological convergence because the potential of the new technologies resides in their ability to connect domains of knowledge that were hitherto apart. Research capacity is important but not sufficient to cross integrative barriers. Communication and networking are all important and fundamental aspects, in line with social network theories that stress complementary of perspectives and connections between actors located in different settings. The uncertainty surrounding the research outcomes in this sector are much higher and qualitatively different from the uncertainty of research activities in other high tech sectors, like for instance 
the telecommunications or information technology sectors [38], and that positions the topic of convergence and integration in a much more acute manner. The reason is related to the level at which the research is done in this sector and with the accessibility of knowledge that is produced, either in the universities or in firms, which in most cases, work in close collaboration. "much of the knowledge in the diverse disciplines that make up the biotechnology sector is intuitive or tacit, rendering the task of harnessing collective learning especially daunting; the process of drug R\&D cannot be broken neatly into pieces, meaning that the disciplines involved must work in an integrated manner" [38] . The level of codification in other high tech sector, namely information and communication technologies is much higher, permitting an easier integration in a modular fashion, and an ex-ante evaluation and selection of alternatives with the inherent diminishing of uncertainty an risks.

Balconi [3] illustrates further this aspect of differentiation and integration of perspectives between the academic and the industrialists in her study of the microelectronics sector. She argues that the "academic researchers are concerned with radically new problems, with the aim of either creating new products or demonstrating that new unexpected applications can be realized also by resorting to known technologies or by creatively recombining existing concepts" but that they need their work to be validated and so "they look at industry for 'direction' in general, and more specifically for problems to be solved (such as the so called 'brick walls' which hinder technological development in certain areas). This fundamental aspect makes this field of research endogenous with respect to the economic system" (p.1618). The analytical approach of academics, coupled with the more technical stance of industrialists, apparently provides an effective means for the integration and convergence of technology.

The examples shown above seem to point to a very important role of university-industry relations as it regards technological integration and convergence. It is not clear, however, what is the precise nature and impact of the connection between them. What it stands out, even in more recent studies [30] is that university-industry relations are very important and significant, but their impact relative to other communication and transfer mechanisms, like entrepreneurship, is limited. This limitation is dependent on the technology or discipline. Some disciplines are easier to integrate than others (e.g. information and communication technologies), because the knowledge in those disciplines is much more codified, and as such, much more easily accessible and transmitted. However, it also stands out that all the entire dynamics of the convergence process is lengthy, uncertain, and essentially multi-institutional and interinstitutional. Public research labs (including universities but also other research institutions), are important inasmuch as they develop the new principles and approaches that will eventually be integrated, but they do it in a rather compartmented way, making convergence ant integration difficult if not impossible, within their premises. Other groups, and apparently not only, necessarily or exclusively private firms (according to Shinn's concept of researchtechnologists) act as the intermediaries or the brokers that find application potential in the new principles or approaches developed at the former institutions, and they seem to be the actors upon which the integrative efforts seem to fall most. However they seem to do it in a very collaborative way, involving a great number of actors and institutions in that process. In any case, its outcome is unpredictable, not only because it is very difficult to predict which particular technology will be successfully integrated with another, but because, ultimately, it will be the market that dictates the success of the integration effort $[7,11]$.

\section{TYPOLOGIES OF UNIVERSITY-INDUSTRY RELATIONS AND THEIR RELATION TO TECHNOLOGICAL CONVERGENCE}

There are many forms of university-industry relations. It can take the form of a researcher from the university advising and contributing to the resolution of a technical problem in a firm. In can take the form of an organised cooperation like the London Technology Network (LTN), where several universities and companies network in order to facilitate access and transfer of knowledge. Or it can be a very structured and purposeful institutional arrangement, like the Engineering Research Centres (ERCs), an US government initiative, which involved active participation of firms and universities in pre-competitive research and development activities, and related educational activities. The mechanisms for UIR include both formal and informal. The informal mechanisms are much more common than the informal ones. The formal mechanisms (joint labs, spin-off firms and contract research) represent only the tip of an iceberg (see fig. 1).

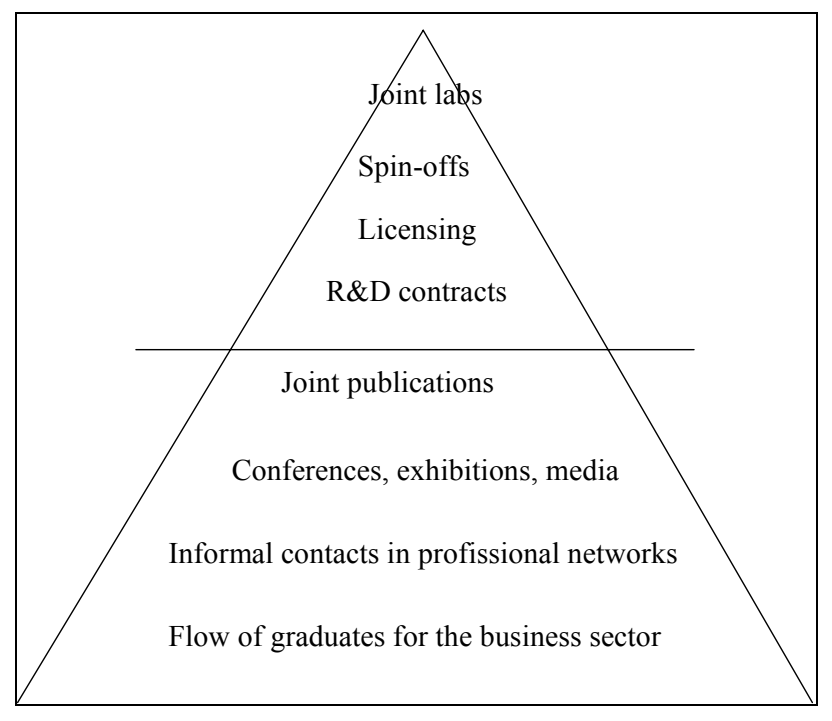

Figure 1: The iceberg of University-Industry relations. Source: [35].

The more common formal mechanism is contract research. Licensing has gained increased acceptance. Most 
universities have implemented policies to exploit their intellectual property holdings, and have established technology transfer offices [29]. However, the majority of UIR are established trough informal contacts and channels (mobility of researchers, co-publications, conferences, exhibitions \& specialised media, informal contacts within professional networks, flow of graduates to industry). This continuum of collaboration mechanisms can be conceptualised in terms of the degree of novelty in the knowledge that is being transferred. On one extreme, the mechanism of graduate flows can be interpreted as the transfer of mature, codified knowledge. In the other extreme, the research joint labs encompass the transfer and the creation of knowledge with a high degree of tacitness. These mechanisms can be related to technological convergence and integration. Convergence and integration are, by nature, activities that require a high degree of novel knowledge and novel approaches. As such, in principle, the forms of industry-university relations more conducive or more appropriate in terms of effectiveness of convergence and integration would those that involve a high degree of tacitness and knowledge novelty.

Diagrammatically, the situation could be represented as in Fig. 2.

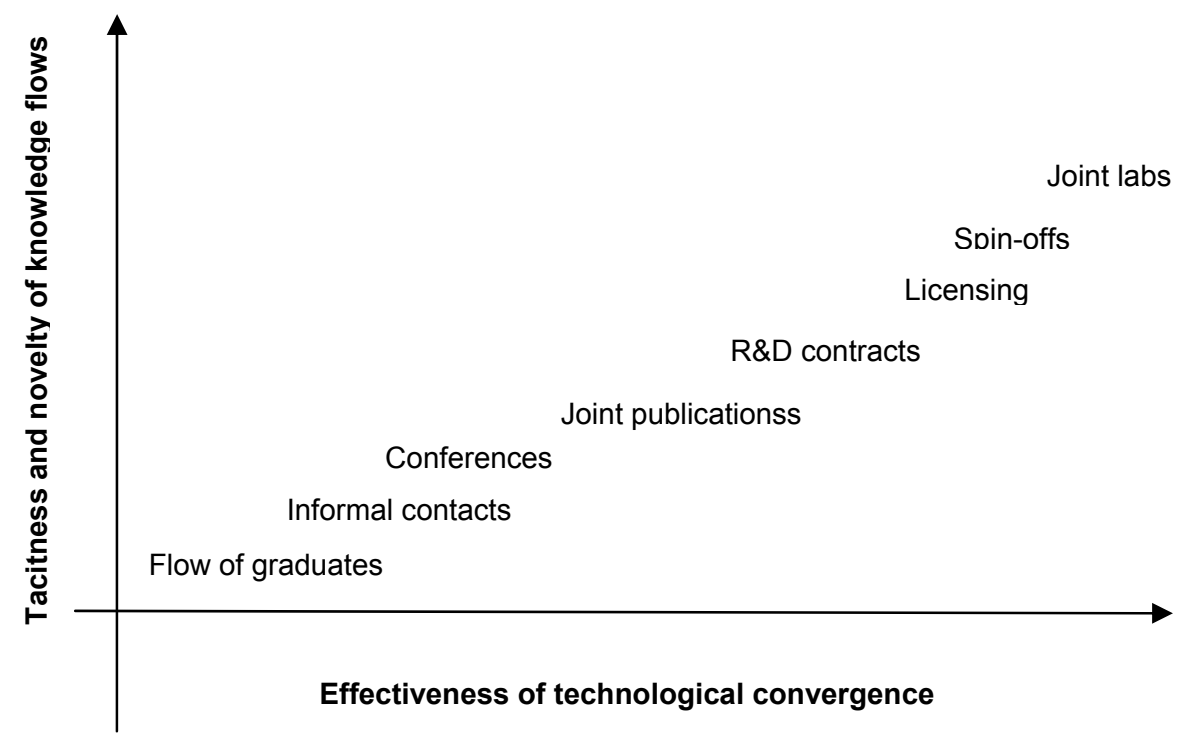

Figure 2: University-Industry Relations and Technological Convergence.

The proposed relationship between modes of universityindustry cooperation and effectiveness of technological convergence, although based in the scattered historical accounts of scientific and technological integration in several fields and sectors, some of them described above, is exploratory and speculative in nature, as there is no strong or systematic empirical evidence that substantiates the model. There is a need for a research agenda based on systematic collection and interpretation of empirical evidence on the qualitative and quantitative aspects of university-industry relations and the implications in terms of determining the most appropriate modes of collaboration, as well as other implications, in terms of convergence and integration of technology.

The need for proper organizational settings and dedicated mechanisms seem to be fundamental to new product development that integrates new and/or existing knowledge. In an empirical investigation of integration activities performed by firms developing mainframe computers Iansiti [22] argues that "...novel concepts, such as may arise from the science base, can be a critical contributor of new knowledge for product development" (p.521) further adding that "...the more effective organizations...exercised a distinct and explicit emphasis on technology integration activities..." (p.522). Although the empirical study from which these observations were drawn was not explicitly dedicated to university-industry relations, there are similarities, since what is at stake is the connection and the integrative capacity between basic science and product development.

However, some policy implications regarding universityindustry relations and technological convergence can be derived from these and the other above assertions. In spite of the fragility of the empirical evidence, what seems to come out is the apparent need of institutional specialization, whereby the universities or other research institutes have a fundamental mission in terms of creation of new fundamental knowledge, whereas other more focused institutions, like firms, new enterprises, or other new forms of collaborative organizations, have a fundamental role in terms of diffusion, application and integration efforts. However, both institutional settings have also fundamental roles in terms of transversal cooperation and communication, competencies that are essential for the effective integration of technology, particularly if the available knowledge has a very strong tacit 
nature. This is a not very new conclusion within the realm of science and technology policy, but the empirical evidence regarding this particular aspect of technological convergence, seems to point to this new old conclusion. It puts again in question the trend towards the privatization of public knowledge (university or public research patenting) and the concerns voiced by many analysts $[15,41]$ regarding the possible impact in terms of diminishing the availability and variability of scientific and technological perspectives, and its long term impact concerning radical product development and economic and social development.

\section{CONCLUSION}

University-industry collaboration has risen in recent years. Network and cognitive advantages have been determinants of this trend. Causes seem to be related to changes in the scientific and technological landscape and the ensuing opportunities perceived by the market and the search for competencies that universities can provide in times of change. Technological convergence presupposes an exploration of new perspective and approaches. Historically, there is evidence that university industry relations are at the realm of the development of radical technologies. Interaction between researchers in academia and researchers or technicians in industry or other institutional settings seem to be a fundamental mechanism in terms of management of technological convergence. Policy implications point to the simultaneous need of institutional specialization and "transversality". An exploratory and speculative model that relates modes of university-industry interaction and effectiveness of technological convergence, based on the properties of the knowledge exchanged, is proposed, and the need for a research agenda that will substantiate the proposed claims is expressed.

\section{REFERENCES}

1. Ahuja, G.; "Collaboration networks, structural holes and innovation: a longitudinal study," Administrative Science Quarterly, 45, 425-455, 2000.

2. Azagra-Caro, J.M., F. Archontakis, A. Gutiérrez-Garcia, and I. Fernandéz-de-Lucio; "Faculty Support for the Objectives of UniversityIndustry Relations Versus Degree of R\&D Cooperation: the Importance of Regional Absorptive Capacity," Research Policy, 35, 37-55, 2006.

3. Balconi, M. and A. Laboranti; "University-industry interactions in applied research: The case of microelectronics," Research Policy, 35, 1616-1630, 2006.

4. Bania, N., R.W. Eberts, and M.S. Fogarty; "Universities and the startup of new companies: can we generalize from Route 128 and Silicon Valey?," The Review of Economics and Statistics, 75, 761-766, 1993.

5. Beaver, D.d.; "Reflections on scientific collaboration (and its study): past, present, and future," Scientometrics, 52, 365-377, 2001.

6. Bonaccorsi, A. and A. Piccaluga; "A Theoretical Framework for the Evaluation of University-Industry Relationships," R \& D Management, 24, 229-247, 1994.

7. Bores, C., C. Saurina, and R. Torres; "Technological convergence: a strategic perspective," Technovation, 23, 1-13, 2003.

8. Burt, R.S.; Structural Holes. Cambridge: Harvard University Press, 1992.
9. Cohen, W.M. and D.A. Levinthal; "Absorptive Capacity: A New Perspective on Learning and Innovation," Administrative Science Quarterly, 35, 128-152, 1990.

10. Cohen, W.M., R.R. Nelson, and J.P. Walsh; "Links and Impacts: The Influence of Public Research on Industrial R\&D," Management Science, 48, 1-23, 2002.

11. Drucker, P.F.; "The discipline of innovation," Harvard Business Review, 63, 67-72, 1985.

12. Faulkner, W. and J. Senker; "Making sense of diversity: public-private sector research linkage in three technologies," Research Policy, 23, 673-695, 1994.

13. Feldman, M., I. Feller, J. Bercovitz, and R. Burton; "Equity and the technology transfer strategies of American research universities," Management Science, 48, 105-121, 2002.

14. Feller, I. and D. Roessner; "What does industry expect from university partnerships?," Issues in Science \& Technology, 2, 1995.

15. Fontana, R., A. Geuna, and M. Matt; "Factors affecting universityindustry R\&D projects: the importance of searching, screening and signalling," Research Policy, 35, 309-323, 2006.

16. Freeman, L.C.; The Development of Social Network Analysis: A Study in the Sociology of Science. Vancouver: Empirical Press. 208, 2004.

17. Geuna, A.; The Economics of Knowledge Production: Funding and the Structure of University Research. Cheltenham: Edward Elgar, 1999.

18. Gittelman, M.; "National institutions, public-private knowledge flows, and innovation performance: A comparative study of the biotechnology industry in the US and France," Research Policy, 35, 1052-1068, 2006.

19. Granovetter, M.; "The Strenght of Weak Ties," American Journal of Sociology, 78, 1360-1380, 1973.

20. Hagedoorn, J.; "Inter-firm R\&D partnerships: an overview of major trends and patterns since 1960," Research Policy, 31, 477-492, 2002.

21. Hagedoorn, J., A.N. Link, and N.S. Vonortas; "Research partnerships," Research Policy, 29, 567-586, 2000.

22. Iansiti, M.; "Technology integration: Managing technological evolution in a complex environment," Research Policy, 24, 521-542, 1995.

23. Kline, S.J. and N. Rosenberg; "An overview of innovation," in The Positive Sum Strategy: Harnessing Technology for Economic Growth, R. Landau and N. Rosenberg, Eds. Washington: The National Academy Press, 1986

24. Lee, Y.S.; "'Technology transfer' and the research university: A search for the boundaries of university-industry collaboration," Research Policy, 25, 843-863, 1996.

25. Leydesdorff, L.; "A methodological perspective on the evaluation of the promotion of university-industry-government relations," Small Business Economics, 20, 201-204, 2003.

26. Meyer-Krahmer, F. and U. Schmoch; "Science-based technologies: university-industry interaction in four fields," Research Policy, 27, 835851, 1998.

27. Miotti, L. and F. Sachwald; "Co-operative R\&D: why and with whom? An integrated framework of analysis," Research Policy, 32, 1481-1499, 2003.

28. Moed, H.F., W. Glänzel, and U. Schmoch; Handbook of Quantitative Science and Technology Research: The Use of Publication and Patent Statistics in Studies on S\&T Systems. Dordrecht: Kluwer Academic Publishers, 2004.

29. Mowery, D.C. and R.R. Nelson; Sources of Industrial Leadership. New York: Cambridge University Press, 1999.

30. Mueller, P.; "Exploring the knowledge filter: How entrepreneurship and university-industry relationships drive economic growth," Research Policy, 35, 1499-1508, 2006.

31. Noble, D.F.; Forces of Production: A Social History of Industrial Automation. New York: Alfred A. Knopf, 1984.

32. National Science Foundation; "Survey of Industrial Research and Development: 2001," Arlington: D.o.S.R. Statistics, 2001.

33. Obstfeld, D.; "Social networks, the Tertius Jungens Orientation, and involvement in innovation," Administrative Science Quarterly, 50, 100$130,2005$.

34. "National Innovation Systems," Paris, 1997.

35. OECD; OECD Science, Technology and Industry Outlook 2000. Paris: OECD, 2000.

36. OECD; Research and Development Statistics. Paris: OECD, 2003. 
37. Owen-Smith, J., M. Riccaboni, F. Pammolli, and W.W. Powell; "A comparison of US and European university-industry relations in the life sciences," Management Science, 48, 24-43, 2002.

38. Pisano, G.P.; "Can Science Be a Business? Lessons from Biotech," Harvard Business Review, 84, 114-125, 2006.

39. Roijakkers, N. and J. Hagedoorn; "Inter-firm R\&D partnering in pharmaceutical biotechnology since 1975: Trends, patterns, and networks," Research Policy, 35 431-446, 2006.

40. Rosenberg, N.; Exploring the Black Box: Technology, Economics and History. Cambridge: Cambridge University Press, 1994.

41. Rosenberg, N. and R.R. Nelson; "American universities and technical advance in industry," Research Policy, 23, 323-348, 1994.

42. Sanchez, A.M. and A.C.P. Tejedor; "University-industry relationships in peripheral regions: The case of Aragon in Spain," Technovation, 15, 613-625, 1995.

43. Senker, J., W. Faulkner, and L. Velho; "Science and technology knowledge flows between industrial and academic research: a comparative study," in Capitalizing knowledge: new intersections of industry and academia, H. Etzkowitz and A.J. Stevens, Eds. Albany, NY, USA: State University of New York Press. p. 111 - 132, 1998.

44. Shinn, T.; "New sources of radical innovation: research-technologies, transversality and distributed learning in a post-industrial order," Social Science Information, 44, 731-764, 2005.

45. Swann, P. and M. Prevezer; "A comparison of the dynamics of industrial clustering in computing and biotechnology," Research Policy, 25, 1139 -1157, 1996.

46. Wagner-Dobler, R.; "Continuity and discontinuity of collaboration behaviour since 1800 - from a bibliometric point of view," Scientometrics, 52, 503-517, 2001.

47. Wilkinson, I. and L. Young; "On cooperating: Firms, relations and networks," Journal of Business Research, 55, 123-132, 2002. 